\title{
The emerging structure of the Extended Evolutionary Synthesis: where does Evo-Devo fit in?
}

\author{
Alejandro Fábregas-Tejeda ${ }^{1,2}\left(\right.$ C) $\cdot$ Francisco Vergara-Silva ${ }^{1}(\mathbb{C}$
}

Received: 14 April 2017 / Accepted: 26 July 2018

c) Springer-Verlag GmbH Germany, part of Springer Nature 2018

\begin{abstract}
The Extended Evolutionary Synthesis (EES) debate is gaining ground in contemporary evolutionary biology. In parallel, a number of philosophical standpoints have emerged in an attempt to clarify what exactly is represented by the EES. For Massimo Pigliucci, we are in the wake of the newest instantiation of a persisting Kuhnian paradigm; in contrast, Telmo Pievani has contended that the transition to an EES could be best represented as a progressive reformation of a prior Lakatosian scientific research program, with the extension of its Neo-Darwinian core and the addition of a brand-new protective belt of assumptions and auxiliary hypotheses. Here, we argue that those philosophical vantage points are not the only ways to interpret what current proposals to 'extend' the Modern Synthesis-derived 'standard evolutionary theory' (SET) entail in terms of theoretical change in evolutionary biology. We specifically propose the image of the emergent EES as a vast network of models and interweaved representations that, instantiated in diverse practices, are connected and related in multiple ways. Under that assumption, the EES could be articulated around a paraconsistent network of evolutionary theories (including some elements of the SET), as well as models, practices and representation systems of contemporary evolutionary biology, with edges and nodes that change their position and centrality as a consequence of the co-construction and stabilization of facts and historical discussions revolving around the epistemic goals of this area of the life sciences. We then critically examine the purported structure of the EES— published by Laland and collaborators in 2015-in light of our own network-based proposal. Finally, we consider which epistemic units of Evo-Devo are present or still missing from the EES, in preparation for further analyses of the topic of explanatory integration in this conceptual framework.
\end{abstract}

Keywords Extended Evolutionary Synthesis $\cdot$ Evolutionary biology $\cdot$ Paradigm $\cdot$ Scientific research program $\cdot$ Epistemic units $\cdot$ Evo-Devo

\section{Introduction}

The American paleontologist Niles Eldredge, famous coproponent of the theory of punctuated equilibrium, recently asserted that "(e)volutionary biology is a notoriously diffuse field of scientific inquiry" (Eldredge 2008; p. 10). Ten years after that statement, the idea seems to hold as the discipline

Alejandro Fábregas-Tejeda

fabregas_alejandro@ciencias.unam.mx

Francisco Vergara-Silva

fvs@ib.unam.mx

1 Instituto de Biología (Jardín Botánico), Universidad Nacional Autónoma de México, Circuito Exterior Ciudad Universitaria S/N, 04510 Mexico City, Mexico

2 Posgrado en Filosofía de la Ciencia, Universidad Nacional Autónoma de México, Mexico City, Mexico comprises a plural landscape of multiple co-existent conceptual frameworks and strenuous voices that disagree on the nature and scope of 'evolutionary theory' (e.g., Oyama 1986; West-Eberhard 2003; Kirschner and Gerhart 2005; Dieckmann and Doebeli 2005; Lynch 2007; Hoekstra and Coyne 2007; Duboule 2010; Laubichler 2010; Wagner 2011; Depew and Weber 2011; Nei 2013; Jablonka and Lamb 2014; Laland et al. 2014, 2015; Futuyma 2015; Pavličev and Wagner 2015; Jaeger et al. 2015; Pievani 2016a; Eldredge et al. 2016; Welch 2017; Charlesworth et al. 2017). Within this plural landscape, a public debate is gaining ground (see Laland et al. 2014): whether a 'new' conceptual framework, i.e., the Extended Evolutionary Synthesis (EES), is needed to extend or go beyond the boundaries and explanatory power of the Standard Evolutionary Theory (SET), the purported direct heir of the Modern Synthesis (MS; in contrast, see Stoltzfus 2017). 
This idea is not precisely novel (it is present, for example, in Waddington 1969; Gould 1980; Stanley 1981; Bonner 1982; Eldredge 1985; Wicken 1987; Endler and McLellan 1988): throughout the twentieth-century, numerous calls for a 'New Synthesis' came from diverse, manifold, and-in some cases-unrelated paleontological and neontological trenches [see Depew and Weber 2013 for a brief overview; see also Callebaut 2010 and Peterson 2016; for a discussion about Niles Eldredge's 'Hierarchy Theory of Evolution' (HTE), a previous attempt to extend the MS from palaeontological grounds and the study of macroevolution, in relation to the concepts and themes espoused in the EES, see Fábregas-Tejeda and Vergara-Silva 2018]. But this time, the framework known as EES ${ }^{1}$ portrays itself in a different light with a far-reaching purview to counteract the explanatory shortcomings of the SET (Laland et al. 2014, 2015). The 'intellectual movement' that publicly started as a published article in the journal Evolution authored by the ItalianAmerican evolutionary biologist and philosopher Massimo Pigliucci-in 2007, where the term 'Extended Evolutionary Synthesis' was coined—soon led to a workshop organized by Gerd B. Müller and Pigliucci at the Konrad Lorenz Institute for Evolution and Cognition Research (Klosterneuburg, Austria), out of which a (now widely discussed) volume arose (see Pigliucci and Müller 2010a). These events were followed by the publication of several articles (e.g., Craig 2010; Noble et al. 2014; Laland et al. 2014; Pigliucci and Finkelman 2014; Noble 2015; Laland et al. 2015; Pievani 2016b) and the organization of a number of scientific meetings dealing with the contours, limitations, challenges and philosophical debates raised by the so-called EES. So far, the EES has exhibited a constellation of social features not seen before in other calls to extend the MS and/or the SET, mainly reflected in considerable institutional and financial support-for instance, the award of an important grant provided by the John Templeton Foundation in 2016 to a group of international scholars, led by Kevin Laland (University of St Andrews) and Tobias Uller (Lund University), to "put

\footnotetext{
${ }^{1}$ Before moving forward, we point out that our discussion will be centered mainly around the ideas and concepts espoused in the book edited by Pigliucci and Müller (2010a, b) and in Laland et al. (2015), which constitute the mainstream usage of the framework dubbed 'Extended Evolutionary Synthesis,' but we recognize that many other authors in recent years have proposed diverse views as to how to 'extend' (or 'expand') the current evolutionary synthesis (e.g. Gould 2002; Kutschera and Niklas 2004; Brooks 2011 and citations therein; Tëmkin and Eldredge 2015 for an updated version of the 'Hierarchy Theory of Evolution' (HTE) that incorporates network analysis; see also Pievani 2016a; Eldredge et al. 2016). In the literature focused on the integration of non-genetic heritable variation into wider evolutionary frameworks, somewhat interchangeable terms to refer to some of the themes and motifs of the EES are being used, e.g. 'Inclusive Evolutionary Synthesis' (Danchin 2013) or 'Pluralistic Model of Inheritance' (Bonduriansky 2012). Differences are more explicit in Bonduriansky and Day (2018).
}

the predictions of the EES to the test' (see, e.g., http://syner gy.st-andrews.ac.uk/ees/the-project/; http://extendedevoluti onarysynthesis.com/the-project/summary-of-our-research/). Further interdisciplinary projects, press attention (e.g., Pennisi 2016, 2008; Whitfield 2008; Grant 2010; Zimmer 2016; Kiger 2016) and the involvement of a large group of evolutionary biologists, philosophers of science and social scientists from a wide-range of academic backgrounds that share explanatory goals and agendas (see http://extendedevoluti onarysynthesis.com/people/) strengthen this picture, at the same time epistemological and sociological.

Nevertheless, lingering philosophical questions remain for historians and philosophers of biology to address: What is the nature of the ongoing change and what type of conceptual architectures are to be expected from the EES? What exactly does the EES 'stand for,' and what would be entailed by resignifications of concepts already defined in/by the SET? In this article, we will outline the different philosophical proposals that have emerged so far as attempts to conceptualize the emerging structure of the EES and its position and significance within contemporary evolutionary biology. Here, we should acknowledge that the evaluation of the merit, utility or intellectual contribution of the variety of models combined under the label of the EES is an important subject that nevertheless lies beyond the scope of this article. That discussion is being actively held between scientists defending that standpoint (e.g., Laland et al. 2015; Müller 2017) and their opponents (e.g., Welch 2017; Futuyma 2017), which includes assessments of specific aspects of the EES (e.g., a critical appraisal of the notion of 'reciprocal causation' in the EES is presented by Svensson 2018). After recounting the philosophical proposals that have been propounded to conceptualize the emerging structure of the EES, we will put forward an alternative interpretation and further discuss the topic of explanatory integration in this conceptual framework, focusing on evolutionary developmental biology (EvoDevo sensu Müller 2007a) as a case study. The last point should be considered preliminary, though, pending analysis in the context of recent proposals of a 'theory of theory integration' (see Laubichler et al. 2018) which have paid special attention to evolutionary biology-related concepts and issues. We will begin with Massimo Pigliucci's personal account and philosophical standpoint about the EES.

\section{The 'Extended Evolutionary Synthesis' (EES): what is the nature of the ongoing change and what type of conceptual architectures are to be expected?}

A common held idea within the minds of natural scientists, although severely criticized by historians and philosophers of science, is that theoretical syntheses not only have been 
accomplished throughout the complex histories of their particular disciplines, but also represent the paragon of something desirable and worth-pursuing in the future (Casanueva and Martínez 2014), i.e., the embodiment of a 'rational success' (see, for instance, Sidlauskas et al. 2010). For models of continuous scientific change, the cases of intertheoretic reduction or assimilation with mild corrections receive positive assessments because, by subsuming previous achievements under novel, wider frameworks, science can develop by successive augmentations and unifications (Casanueva and Martínez 2014). This is the mindset glanced in Massimo Pigliucci's account of the conceptual history-and uninterrupted expansion of the conceptual repertoire-of 'evolutionary theory', from Darwinism to the recent discussions and reevaluations put forth by the EES (see Pigliucci 2009). In that article, Pigliucci embraced a position that we call 'unicity of evolutionary thought': for him, evolutionary biology is composed of a single conceptual framework cemented by the ideas of Charles Robert Darwin and Alfred Russell Wallace that has been modified, refined, expanded and assembled in a step-wise manner during historically important instantiations (i.e., 'Neo-Darwinism,' 'Modern Synthesis' and 'Extended Evolutionary Synthesis'), represented as a nested set of ellipses in Pigliucci's original diagram. ${ }^{2}$ In his own words: “(...) evolutionary biology has not undergone a paradigm shift since Darwin and Wallace's work" (Pigliucci 2009; p. 219; a key viewpoint also underscored in Pigliucci 2007). By explicitly embracing Kuhnian notions, Pigliucci argues that evolutionary biologists have reacted to various minor crises by means of augmenting the preexisting framework, constructing new floors in their robust structure, without shaking or undermining its Darwinian foundations (Pigliucci 2007). Likewise, in recent times Pigliucci has stated that no methodological, observational or semantic incommensurability exists between the EES and the 'Darwinian Paradigm' (see the talk 'Extended Evolutionary Synthesis and paradigm shifts' available at

\footnotetext{
2 The visual tradition for depicting the EES as a nested set of ellipses (a Venn diagram), initiated by Pigliucci (2009), has been influential for many evolutionary biologists and philosophers. For example, taking Pigliucci's diagram as a starting point, the British physiologist Denis Noble recently published his take on the contours of the EES (Noble 2015), for him dubbed 'Integrative Synthesis' as it would be based on the integration of a variety of interacting mechanisms of evolutionary change; he sees it as "a nuanced multi mechanism theory of evolution" (Noble 2015; p. 7). The differences between the two diagrams are conspicuous: at variance with Pigliucci, Noble does not portray the 'new synthesis' as a perfectly continuous extension of the MS: several elements of its gene-centric stance will be left out, being replaced by wider views of inheritance, multilevel selection and a different view of genomic evolution. Instead of using a nested set of enlarging ellipses, Noble depicts the EES as a set of partially overlapping ellipses (with elements of the MS not in contact with the elements of the purported EES)
}

his website https://platofootnote.wordpress.com/talks/; see also Pigliucci 2018). According to this view, contemporary evolutionary biology (and the EES debate within it) is seen as an unscathed edifice of puzzle-solving 'normal science'. Hence, in our interpretation, Pigliucci's answer to the question posed earlier is that we are in the wake of the newest instantiation of a persisting Kuhnian paradigm.

This vantage point, in its extreme form, grants that there is but 'one Theory of Evolution' in the twenty-first century, bequeathed by the sustained efforts of multiple scientists, whose conceptual contributions can be, in principle, aligned with unbroken historical continuity. Veiled in this alleged consecutive advancement of 'evolutionary theory' could lie an unrecognized projection of how things ought to unfold in the future. Citing the last sentence of Pigliucci's 2009 article: "Because of the very nature of science, there is no pretense at all that the third ellipse will be the end of the story"; mirroring the past, new instantiations of "evolutionary theory' will be defined and delimited in the horizon of future ideas, phenomena to be studied and fields of inquiry, suggesting an endless spiral-progressive but perfectibleof conceptual expansion (see Fig. 1). However, this is an over-simplistic view of the history, present state and future projections of evolutionary biology as a scientific discipline (see also Delisle 2018; p. 158): history cannot be used to accurately predict the future (see Gaddis 2002) and, as robust historiography of science shows, scientific knowledge does not accumulate in a linear and progressive fashion (e.g., Raj 2013; for a contextualized example in the history of evolutionary biology, see Amundson 2005). ${ }^{3}$

At the same time, many historians and philosophers would disagree with the portrayal of 'persisting paradigm' that Pigliucci ascribes to evolutionary biology-first of all, as has been argued many times, Kuhnian notions such as 'paradigm' or 'exemplar' prove to be flawed, or at least very difficult to apply, for the case of biology (see, e.g., Lewens 2016; Peterson 2016). Philosophers of biology such as Telmo Pievani (2012) openly disagree with the characterization of current evolutionary theory as a Kuhnian paradigm on the grounds that no serious anomalies have accrued in the last century, and that there is no tangible 'dogmatic crystallization' or 'hardening' that announces a major crisis and a subsequent paradigm shift. Instead, Pievani (2012, 2016a) argues that is commonplace in the field of evolutionary biology to solve and understand new problems and apparent exceptions mainly through integrative explanations, fine adjustments of the breadth of application of established forms of explanation to distinct empirical domains, novel

\footnotetext{
${ }^{3}$ It should be mentioned that Pigliucci's stance on the current juncture and the future of evolutionary thought has become more nuanced in recent years (see Pigliucci and Finkelman 2014; Pigliucci 2018).
} 


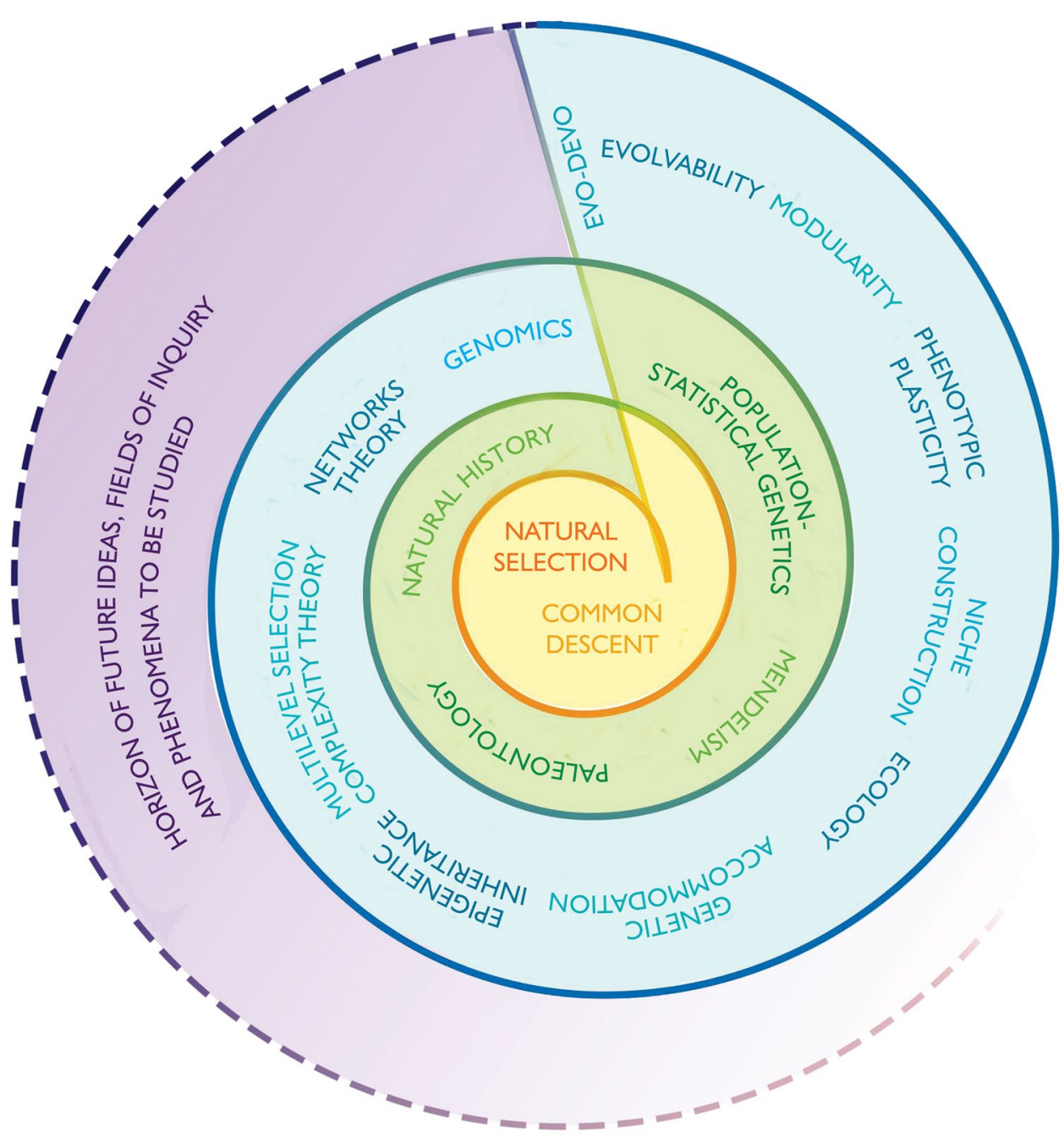

Fig. 1 Conceptual representation, based on Pigliucci (2009), of the continuous expansion of 'evolutionary theory' in terms of ideas, phenomena studied, and fields of inquiry. The conceptual elements portrayed in the diagram reflect Pigliucci's original choices (2009) - even though we strongly disagree with the epistemic location of Natural History, Paleontology and other entities-, with the only exception of disbanding and rewording the pairings of concepts (evolvability and modularity; plasticity and genetic accommodation). Instead of depicting the alleged consecutive advancement using a nested hierarchy of ellipses (see Pigliucci 2009), we chose the graphic representation of an endless spiral of expansion. The multicolored line demarcates the boundaries of the historically important instantiations of evolutionary theory (i.e., Darwinism, Modern Synthesis, Extended Evolutionary Synthesis). The yellow set represents Darwin's theory; the green set is the Modern Synthesis; the blue set corresponds to the Extended Evolutionary Synthesis; and the purple set enclosed in dotted lines hint at possible future expansions of evolutionary theory. The relative distance between the elements is not intended to reflect closer conceptual ties; likewise, the relative order of appearance of the elements throughout the spiral does not imply chronological developments. Image conceived by Fátima Sofía Ávila-Cascajares and Alejandro Fábregas-Tejeda; image design by Casandra Lizbeth Méndez-Martínez, Diana Martínez Almaguer and Julio César Montero Rojas (color figure online) calculations of the relative frequency of occurrence of evolutionary patterns, and by means of updating the evolutionist's theoretical tool-kit and plodding along experimental novelties. That means that "(...) the dynamics of growth and evolution of the theory is based on processes of theoretical extension and empirical enlargement of an elastic set of explanations already consolidated but constantly needing adjustments and integrations" (Pievani 2012; p. 214). Furthermore, for this author the notion of a 'scientific research program' (SRP; sensu Lakatos 1978) best captures the intricacies of the non-static set of articulated explanations of evolutionary biology (Pievani 2012). In contrast to the discontinuous shifts of Kuhnian paradigms, Lakatosian scientific research programs change in a continuous fashion and allow for amendments and processes of updating (Suman 2016). Pievani (2012) also makes the case that the ongoing transition from the MS to an EES could be best represented as a progressive reformation — and not a blunt 
substitution - of a prior evolutionary research program with a different one that displays an extended Neo-Darwinian core, surrounded by a brand-new protective belt of epistemic assumptions and auxiliary hypotheses with a pluralistic and integrative explanatory approach. The core of the evolutionary biology SRP known as MS is depicted by Pievani as the genetic and populational theory of natural selection; accordingly, three major methodological postulates comprise the external protective belt: phyletic gradualism, extrapolationism from microevolution to macroevolution, and stringent adaptationism (Pievani 2012; for a contrasting characterization, see Futuyma 2015). Pievani therefore thinks that the EES entails a steady and irreversible transformation of the architecture of the previous SRP (i.e., a new protective belt and an expanded core), and not merely a superficial styling on marginal points of a hardened structure. In that sense, the structure of the new SRP would contain profound conceptual novelty and pluralistic frameworks while remaining compatible with the core of the MS (Pievani 2012).

A similar version of that view, which instead portrays the EES as an alternative Lakatosian research program to the SET - and not the reformation of such theoretical assemblage-was expounded and discussed during the 2016 meeting 'New trends in evolutionary biology: biological, philosophical and social science perspectives' held at the Royal Society of London, and is now reaching for consensus among the international community of scientists and philosophers that support the EES movement. At the aforementioned meeting, during the first round table discussion moderated by the British philosopher of science Nancy Cartwright (8 November 2016), Kevin Laland stated that, in his opinion, the EES is an alternative (and complementary) Lakatosian research program to the SET (audio recordings of the presentations are available at https://royalsociety.org/ science-events-and-lectures/2016/11/evolutionary-biology/). This is the discursive presentation of the EES that was hinted in Laland et al. (2015), and the one that explicitly appears in the recently inaugurated website of the EES, linked with the project financed by the Templeton Foundation (see http:// extendedevolutionarysynthesis.com/).

It is important to stress that, for the current state of affairs in the plural landscape of evolutionary biology, characterizing the EES with Lakatosian schemes is not a move free of drawbacks. According to the evaluative typology Lakatos (1978) proposed for SRPs, a program can be progressive during a limited timeframe if it is able to make successful predictions and increase the number of statements and hypotheses with empirical content; on the contrary, a program can be degenerative if it only resorts to ad hoc explanations to account for novel observations. Notwithstanding that apparently clear-cut distinction, Lakatos emphasized that tables can be turned at any moment: a successful program may start to degenerate and a competing program could overcome a rough patch, becoming progressive once again. Moreover, at this point it is necessary to remember that the methodology proposed by Lakatos is exclusively retrospective: it provides neither forward-looking assessments of present competing scientific research programs, nor delineates strong criteria to rationally conduct the business of theory appraisal (for an analysis, see Hacking 1979). His friend and colleague, Paul Feyerabend, fiercely criticized Lakatosian methodology—in the book Against Method (1975)—because it 'could not function as a good device' for advising on current scientific work. For Lakatos himself, the progressiveness or degeneracy of a SRP could only be asserted through historiographical work; thus, by resorting to Lakatosian schemes, the proponents of the EES cannot claim that the SET should be abandoned because their conceptual framework is, in some sense, superior (as was hinted in Laland et al. 2014; a position that was later changed in Laland et al. 2015), if they wish to remain congruent with the philosophical standpoint they openly chose. Furthermore, even though the entire list of predictions (delineated in Laland et al. 2015) set to be tested by the Templeton Foundation's project turned out to be successful, the proponents of the EES cannot claim that their research program will entail future achievements and that it is progressive (for Lakatos, that is something only historians can decide). According to Lakatos, successful predictions do not guarantee, by any means, future successes: the EES can start in a progressive path and end up in disparagement, being overpassed by a renewed SET. In Lakatosian terms, then, the EES movement could prove to be transitory, and subject to the rhetoric and sociological contexts of evolutionary biology that surely will unfold in the next few years.

The Modern Synthesis was articulated and elaborated around the time a strong and over-arching tradition of philosophy of science (i.e., logical empiricism) was gaining ground $^{4}$ (for historical and philosophical overviews, see Smocovitis 1996; Callebaut 2010, respectively). Although not mentioned or recognized very often, the architects of the MS and logical empiricists shared epistemological commitments (Delisle 2009): ideals of a unified science and compact explanatory structures capable of dealing with numerous and multifarious phenomena. There are communicating vessels between this philosophical heritage and the interpretations that regard the Extended Evolutionary

\footnotetext{
${ }^{4}$ In the traditional narratives, it was not until a few decades later that what we properly call 'philosophy of biology' was born (Palma 2015). Philosophy of biology integrated aspects, reformulations and critiques to the blind spots and flaws of twentieth-century philosophy of science-e.g. the rejection to strict determinism, 'universal laws' and physicalist epistemologies, accepting, instead, probabilistic predictions and historical explanations (see Mayr 2004) —as well as the unique theoretical and empirical developments of a mature biology (Palma 2015). For a different and robust historiography on the origins of philosophy of biology, see Nicholson and Gawne (2015).
} 
Synthesis as a unification-a new compact explanatory structure - of disparate concepts, puzzling phenomena and scientific disciplines, such as the vision portrayed in Fig. 1 (for a discussion, vide supra). Framing the EES as a persisting Kuhnian paradigm or as an alternative Lakatosian research program are not the only possible philosophical avenues to think about theoretical change or the possible interpretations of what the label 'Extended Evolutionary Synthesis' stands for ${ }^{5}$ and what resignifications may entail. We think that maybe the right metaphors of scientific change are not at play. It is relatively easy to use worn-out notions such as 'paradigm' or 'scientific research program'. A bigger challenge for philosophers and historians of biology is to come up with different metaphors or models of scientific change to comprehensively characterize the structure of scientific frameworks. We agree with Love (2010) that there is no 'one and only' correct way of thinking about evolutionary theory (or theories, we may add) and that epistemological perspectives should be discussed in a 'pluralistic stance' (sensu Kellert et al. 2006), gauging the alternatives with its advantages, disadvantages, biases and heuristic values. Contrary to the pursuit for the hegemonic ascent of a single view to apprehend the EES, we prefer alternative images in which pluralism can thrive (see Casanueva 2016). In what follows, we propose one of such outlooks in order to start the discussion, though we do not claim that it is an unblemished view.

\section{Alternative interpretations of the 'emerging structure' of the EES}

For evolutionary biologists, there is a pervasive tendency to think that "evolutionary theory [here referring to the theoretical structure or the central tenets of the MS] is a cohesive unit, which maintains a single structural packaging of its theoretical content" (Love 2013; p. 327; text inside brackets added). On the other hand, many philosophers of biology have contended that the MS cannot be represented as a single comprehensive scientific theory (e.g., Wassermann 1981; Burian 1988; Callebaut 2010; Love 2013). Werner Callebaut (2010) characterized the 'evolution of evolutionary thinking', since the onset of the MS, as an open-ended dialectical history of simultaneous unifying and disunifying tendencies: this comment bolsters the view that it is more suitable to think of the MS as a "flexibly structured network of concepts and models" (p. 457) rather than as a

\footnotetext{
${ }^{5}$ Other possibilities would include conceptualizing the EES, just as the MS was conceived in past decades, as a multi-field theory (sensu Darden 1986) or, following Wassermann (1981), as a hypertheory that subsumes subordinate theories that deal with different but complementary evolutionary mechanisms; for additional discussions, see Love $(2013,2017)$
}

bona fide theory, as they are usually conceptualized by classical philosophical traditions. Accordingly, we do not see the EES as a single theory or as something akin to a new compact explanatory structure revolving around a unified core (something Pigliucci 2009, Fig. 1 and the other portrayals of the EES revised before seem to imply; see also Reiss 2012). The invocation of spatial containment metaphors to depict the EES (remarkably, the image of a nested set of ellipses or its variations that presume that what is needed to extend the MS/SET is merely to enlarge its conceptual bucket) is followed by another unwanted assumption: that its theory structure is relatively uncomplicated, consisting of an organized system with a central core and some regional satellites, although their specifics relations remain unstated (Love 2013; see also Love 2017 for other critiques of the inadequacy of spatial containment metaphors to characterize evolutionary biology).

Alternatively, we think that the mature structure of the EES might not be characterized by a new harmonious set of perfectly consistent theories (in contrast to what has once been claimed for the case of the MS, see Mayr 1963; p. 8). Instead, we propose the image of a large network of models and interweaved representations that, instantiated in diverse practices, are connected and related in multiple ways. ${ }^{6}$ In their review of Pigliucci and Müller (2010a), Handschuh and Mitteroecker (2012) informally suggested that the gestation and maturation of the EES, in an analogy to the historical development of the MS, can follow defined stages: after the expansion of the remodeled MS framework by adding concepts of innovative research fields (i.e., the second stage of their periodization), a new core, much more diverse and thus much looser in interdependency, could be accepted by consensus, "integrating the spectrum of concepts to a weblike theoretical network" (p. 19). This view is different from ours because we think that the EES could be articulated around a paraconsistent network (or group of networks) of evolutionary models, practices and representation systems, with edges and nodes that change their position and centrality as a consequence of the co-construction and stabilization of facts and historical discussions revolving around the epistemic goals of evolutionary biology.

\section{Units and goals in the epistemology of the EES}

Epistemic goals are complex scientific problems consisting of a set of related questions (Brigandt 2010). Ingo Brigandt (2010) recognizes these are synonyms to Alan Love's notion of 'problem agenda' (see Love 2008, 2010). Love (2010) has suggested an "erotetic (pertaining to questioning) structure for

\footnotetext{
${ }^{6}$ This idea emerged in the context of an academic collaboration with Mexican philosopher of science Mario Casanueva López (UAM-Cuajimalpa, Mexico).
} 
evolutionary theory, which characterizes a synthesis in terms of multiple problem agendas exhibiting complex but coordinating relationships" (p. 404). Each epistemic goal or problem agenda is associated with 'criteria of adequacy', which, given current empirical and conceptual background knowledge, set standards for what counts as an adequate solution (i.e., what shape a satisfactory explanation has to take), thus forming the overall explanans for a particular explanandum (Brigandt 2010). For example, an epistemic goal for Evo-Devo (or, as some would claim, for contemporary evolutionary biology as a whole) is the explanation of evolvability (Wagner 2015; Nuño de la Rosa 2017) and evolutionary novelties (Brigandt 2010; Brigandt and Love 2010, 2012). In contrast, as stated by Pigliucci and Müller (2010b), a primary goal for an 'extended synthesis' - and/ or for the EES-is to provide a causal-mechanistic account of phenotypic evolution. To be sure, an epistemic goal for the EES sensu Laland et al. (2015) is to give a mechanistic explanation of the origin and maintenance of functional and selectable phenotypic variation (with its genetic and non-genetic sources). Another important epistemic goal for the EES is to understand the constructive roles organisms play shaping their own development and evolution, and how they change their environments (through niche construction and other ontogenetic processes) in evolutionary meaningful ways (Laland et al. 2015).

In our scheme, classic Neo-Darwinian elements (e.g., natural selection) would not be at the center or core of this imagined diffuse network (because it will be devoid of one) but would most likely be hubs in a more distributed and inclusive conceptual system of connections (for a different rebuttal of the idea of 'core' in evolutionary biology, see Love 2013). In this view, some local regions of the dynamical network(s) ${ }^{7}$ would be more robust than others, but none would remain strictly fixed. Such conceptual architecture of the EES would allow explanatory schemes of multilevel causation (sensu Martínez and Esposito 2014), pertinent to the undeniable ontological complexity of biological processes (e.g., morphogenesis) that involve systemic properties across several levels of organization.

In the current state of affairs, whereas portrayed as a big change (see the 'Yes, urgently' standpoint in Laland et al. 2014) or as a more nuanced pluralistic alternative framework that hinders the hegemony of the 'traditional view' (see Laland et al. 2015), the EES is beginning to outline its structure with a representation not as tidy as a single 'theory', but with a

\footnotetext{
$\overline{7}$ A possibility that may be worth exploring further is that, for a given moment in time, there could be more than one topological configuration of the EES existing simultaneously. For Love (2013; p. 332), in evolutionary biology we can see a “(...) multiplicity of theory structures constructed from the heterogeneity of methodological and epistemological goals" (italics added); in the future, if the EES reaches far-ranging acceptance, we could have many EES structures in the cases where distinct situated communities of evolutionary biologists follow different epistemic goals.
}

much more complex picture bearing resemblance to a diffuse net (Fig. 2). The framework of the EES emphasizes the role of constructive processes in development and evolution, a broader conception of transgenerational inheritance that encompasses many forms of non-genetic variation, and reciprocal representations of causation (Laland et al. 2015). Laland et al. (2015) grant that the impetus for an EES is "undoubtedly complex and multifaceted" (p. 3); nevertheless, they deemed convenient to concentrate their arguments about the incipient structure, assumptions and predictions of the EES on insights derived mainly from four research areas with convergent themes: in their own usage, "developmental plasticity", "inclusive inheritance", "niche construction", and "evolutionary developmental biology" (hence leaving out of the account some important subjects, such as physiology, that had been already discussed under extended evolutionary schemes, see Noble et al. 2014).

There is no question that the paper by Laland et al. (2015) was a commendable first effort to construct a coherent structure for the EES, since one of the main criticisms it had received by then from multiple camps is that the notion of an 'Extended Evolutionary Synthesis' is just a grandiloquent label with an unfathomable common theoretical thread, besides fighting the straw-man of gene-centrism (on these points, see the criticism of Pievani 2016a). Notwithstanding the importance of their meaningful effort, we have detected some misunderstandings that arise from their ambiguous usage of 'structure', a tricky philosophical term. The challenges to the SET accentuated by the EES refer to "how evolutionary theory is structured and not simply whether more content must be included" (Love 2017; p. 161). Thorough analyses of the epistemological aspects of science involve making a distinction between the 'structure' and 'content' of theories and conceptual frameworks. Considerations about the structure of theories, for instance, pertain to the nature of scientific theories themselves (Love 2010) and to questions such as: How is knowledge organized within a circumscribed domain called 'theory $X$ '? Does the organization of knowledge of a particular theory resemble other scientific theories? In which ways is different or similar? What are the contours of a scientific theory? Should we organize the content of theories following certain epistemic ground rules? (see Love 2017). For philosophers of science, three families of perspectives on the structure of scientific theories are operative (Winther 2015a): the syntactic view (in which theories are conceived as axiomatized collections of sentences, i.e., syntactic logical reconstructions), the semantic view (where theories are conceived as collections of nonlinguistic models open to semantically meaningful mathematical modeling), and the pragmatic view (according to which theories are conceived as amorphous and complex entities closely tied to function and context, consisting variably of sentences, models, exemplars, problems, standards, skills, practices and tendencies). Regardless of the philosophical standpoint, the issue we want to highlight is that the content of scientific theories gets organized by 


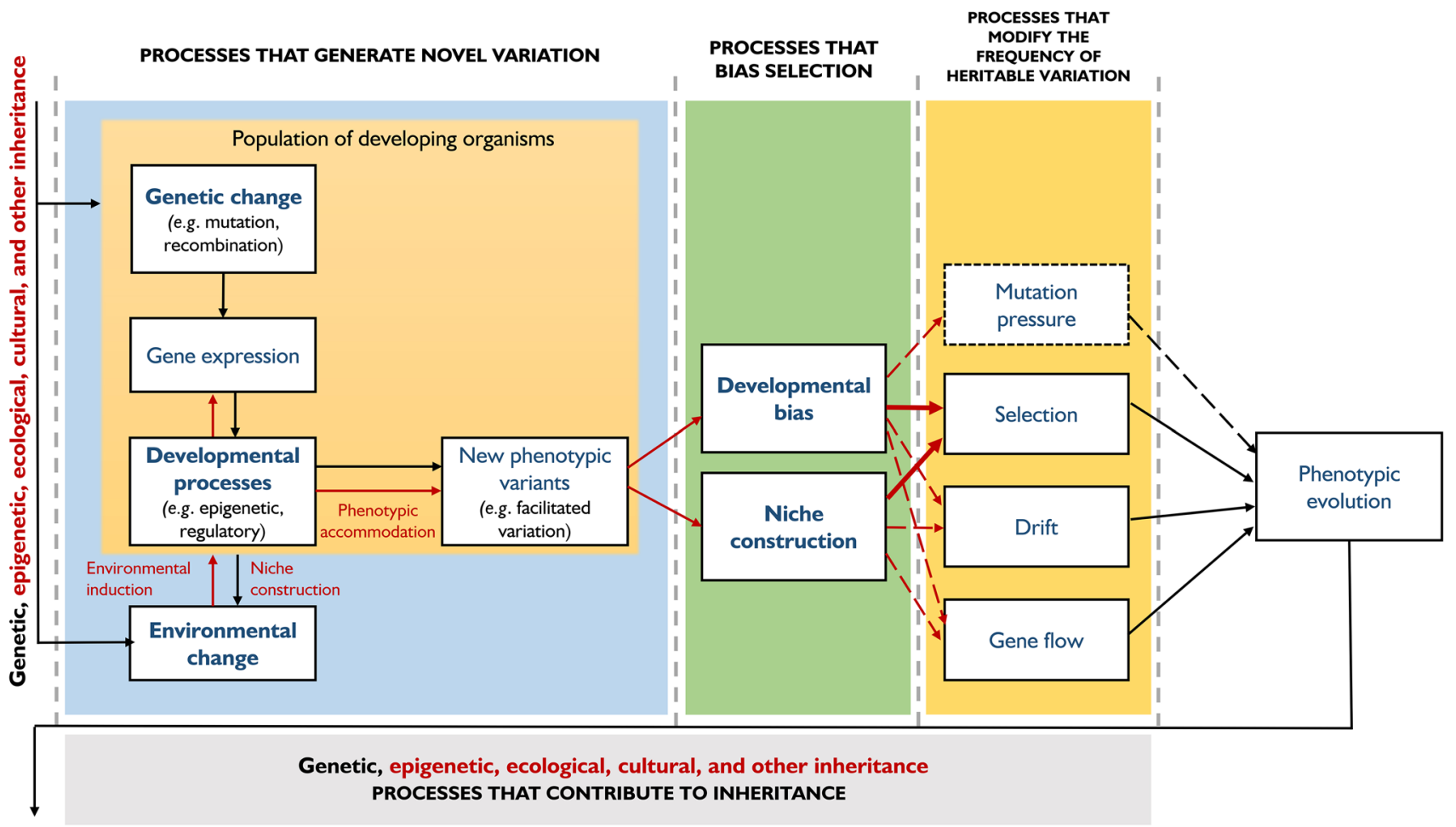

Fig. 2 The recently stated 'structure' of the Extended Evolutionary Synthesis, redrawn and modified from Laland et al. (2015), maintaining the concepts and solid/dotted arrows portrayed there, with indication of the interacting 'processes' that generate novel variants (e.g., genetic change, developmental processes), bias selection (i.e., niche construction and developmental bias), modify the frequency of heritable variation (i.e., evolutionary forces acting in a population genetics context) and contribute to inclusive transgenerational inheritance (a broadened conception that includes genetic, epigenetic, ecological and cultural inheritance). Concepts shown in red are those emphasized and advocated by the EES, but subsumed, disregarded

scientists and philosophers in epistemic units (e.g., models, concepts, exemplars, explanations, problems, practices) that relate to each other in defined ways, thereby delineating a structure. ${ }^{8}$ The purported 'structure' of the EES in Laland et al. (2015) depicts the relations between classic Neo-Darwinian evolutionary causes (e.g., natural selection, genetic drift) and several additional classes of processes that are newly recognized evolutionary causes (including those that generate novel variation, bias selection and contribute to inheritance), without making explicit how the content (i.e., processes important for biological evolution) should be organized in related epistemic units. For a plural conceptual framework such as the EES, the ambiguity of Laland and collaborators' characterization of its 'structure' lies in its uncertainty regarding the organizational representation of (the relevant) evolutionary processes-i.e.,

\footnotetext{
${ }^{8}$ Theories can also be epistemic units for wider conceptual frameworks (e.g. hypertheories, see Wassermann 1981) that embrace several complementary theories or models.
}

or deemed negligible by more traditional perspectives. In their original diagram, concepts here written in bold, in our opinion exhibited ambiguous meanings produced by confusions or not sufficiently explicit distinctions between epistemic units and the ontology of natural processes. The peach-colored rectangle demarcates the boundaries of a population of developing organisms. The blue rectangle encompasses processes that generate novel variants; the green rectangle encompasses processes that bias selection; the yellowish rectangle encompasses processes that modify the frequency of heritable variation. Finally, the gray rectangle encompasses processes that contribute to inclusive transgenerational inheritance (color figure online)

if they are depicted/contained in models, concepts, theories, explanations and/or other epistemic units connected in defined manners. Thematically expanding an evolutionary framework by means of recognizing several additional classes of related evolutionary processes does not suffice to understand the meaningful changes these new components may bring to its conceptual architecture ${ }^{9}$ : the clarification of how knowledge about the processes of evolution is organized into distinct and connected epistemic units (i.e., how content is structured) is needed. We show that in Fig. 3 by projecting in two separate but coordinate planes the recently stated 'structure' of the EES

\footnotetext{
9 A quote from Love (2013; p. 328) is insightful in that regard: “(...) new findings and conceptual developments may involve the reorganization or rearrangement of theory components, even if they do not 'overthrow' existing foundations. Part of the call for an EES could be a complaint about how evolutionary theory organizes biological knowledge and guides inquiry, not simply about whether it contains all of the relevant parts".
} 


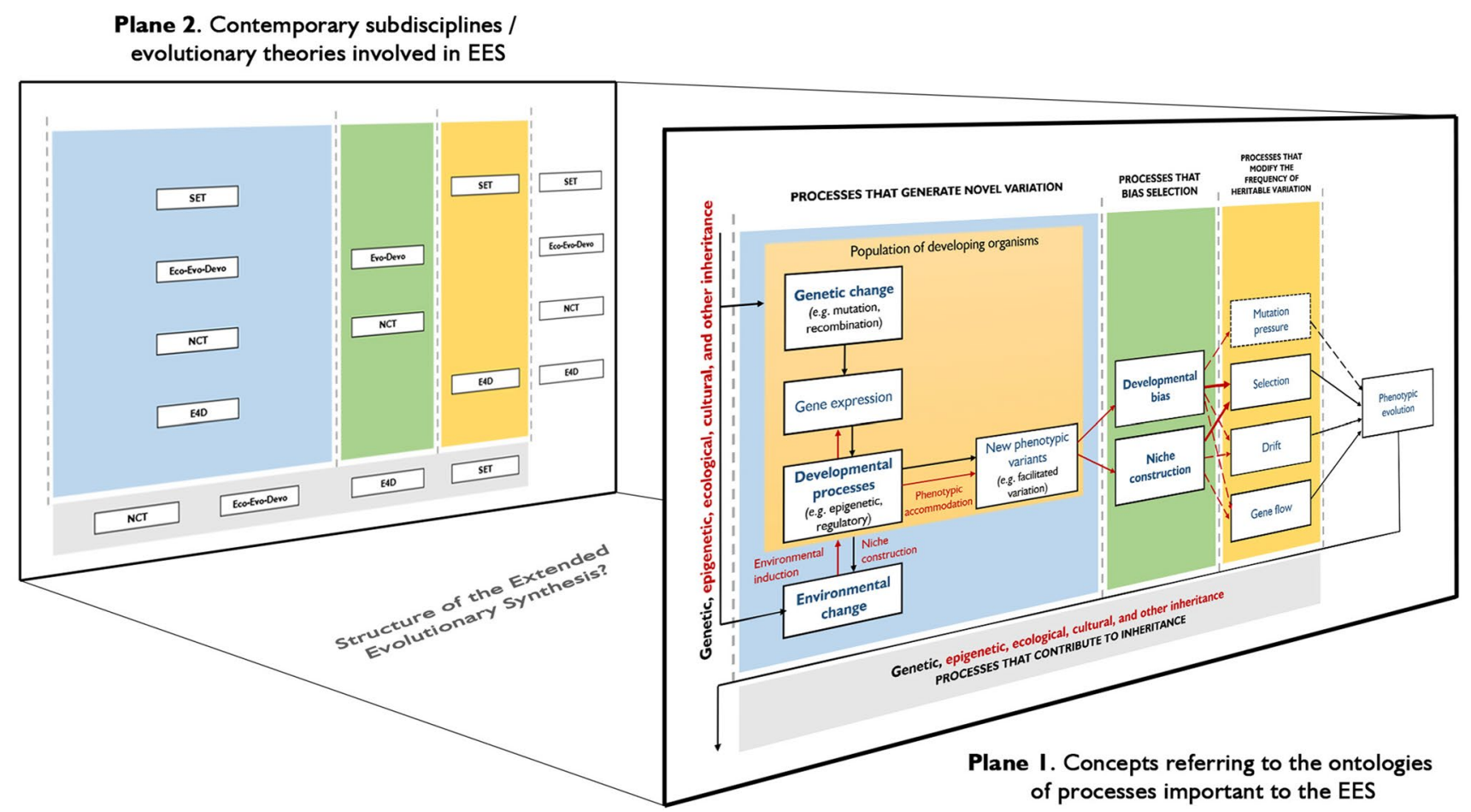

Fig. 3 The recently stated 'structure' of the Extended Evolutionary Synthesis, based on Laland et al. (2015), projected with two separate but coordinate planes: to the right, a plane that accommodates concepts that refer to evolutionary relevant natural processes (reproduced from Fig. 2; 'Plane 1'); to the left, a non-historicized space of contemporary subdisciplines/evolutionary theories that have explored or tried to explain some of the concepts depicted in the other plane (i.e., the purported core concepts of the EES; 'Plane 2'). The colored rectangles, with the same color code used in Fig. 2, chart correspond- ences between the two planes: the four kinds of processes depicted in the right plane have been addressed by different, often interacting, subdisciplines/evolutionary theories. Currently, the structure of the EES is missing but would emerge at the interface of the two planes. SET standard evolutionary theory, Evo-Devo evolutionary developmental biology, Eco-Evo-Devo ecological evolutionary developmental biology, NCT niche construction theory, E4D evolution in four dimensions (color figure online)

into distinct epistemic units and how they relate to each other (i.e., what is the current topology of the structural network). In Fig. 3, the structure of the EES is currently missing but would emerge at the interface of the two planes. Our preliminary analysis of Laland et al. (2015) hints at an emerging conceptual architecture of the EES which resembles a diffuse network (or maybe more than one network) of multiple epistemic units derived from different biological subdisciplines and evolutionary theories/models in complex and pluralistic dialogue, sharing epistemic goals.

It should be stressed that the scientific subdisciplines and models ['Evo-Devo'; 'developmental plasticity' (DP)] and evolutionary theories [('Niche Construction Theory (NCT); 'Evolution in 4 Dimensions' (E4D); 'Standard Evolutionary Theory' (SET)] at play are not represented unabridged: several elements of most of them are missing from the conceptual architecture of the EES (see Laland et al. 2015). To give some examples: interpretative mutations (sensu Jablonka and Lamb 2014) are not mentioned; construction chains, important for depicting causal influences in NCT (see Laland and O'Brien 2012), are not formally integrated

\footnotetext{
$\overline{10}$ We think the notion of 'evolutionary theories' in that context is adequate. Niche construction theory is the prominent example of one (see Odling-Smee et al. 2003; Laland et al. 2016). Eva Jablonka and Marion Lamb have also described the general picture of their book Evolution in Four Dimensions as a "sort of Darwinian theory (...) that sees DNA as a crucial heritable developmental resource, but recognizes that DNA is not the only resource that contributes to heredity" (Jablonka and Lamb 2007; p. 356; see Jablonka and Lamb 2014 for a revised edition of the book).
} 
into the working framework of the EES ${ }^{11}$; epistasis and extinction (important for the defenders of the SET) are being overlooked (see the 'No, All is Well' stance in Laland et al. 2014). This could be a reflection of what Ingo Brigandt has seen as a key component of explanatory integration: "solving a complex problem [an epistemic goal] need not require the stable synthesis of different biological fields or the development of genuine interfield theories, as smaller epistemic units [concepts, explanations, methods] from traditional disciplines can be related solely for the purposes of a specific problem" (Brigandt 2010; text inside brackets added). The next section of this article deals with what epistemic units (sensu Brigandt's epistemology of explanatory integration) of Evo-Devo are present or still missing from the emerging architecture of the EES.

\section{How Evo-Devo and the EES are formally related? What key themes of Evo-Devo are not (yet) formally integrated into the conceptual foundations of the EES?}

In the same way we should be wary of the doubtful characterizations that regard the MS as a single comprehensive scientific theory, we should remain skeptical of the claims that depict present Evo-Devo as a single unified theory (see Nuño de la Rosa 2014 for a brief analysis). Moreover, in recent times, the field has suffered a vertiginous expansion with the incorporation of conceptual and technical tools from many subdisciplines, including genomics, ecological and quantitative genetics, the study of developmental plasticity, ecology, paleontology, cell and systems biology, theoretical biology, behavioral sciences, population genetics and a large etcetera (Abouheif and Sears 2015; a trend originally identified by Müller 2007a). As a consequence, the boundaries of evolutionary developmental biology are becoming blurred and harder to demarcate, and so its goals and questions. This is one of the reasons why it is not at all clear how Evo-Devo should be formally integrated into the current evolutionary synthesis ${ }^{12}$ or into the pluralistic EES. ${ }^{13}$ Of the different calls to 'extend' the MS that have appeared in recent years, the

\footnotetext{
${ }^{11}$ Although one could interpret Fig. 2 as something akin to a construction chain.

12 For three different accounts of the tensions that exist between EvoDevo and the Modern Synthesis, consult Minelli (2010), Laubichler (2010), Craig (2015). They address, respectively, the viable possibility of integration, the insurmountable obstacles for doing so, and the possible pluralist co-existence of both as individual conceptual frameworks in evolutionary biology. Amundson (2005) is a good historical complement to these debates.

${ }^{13}$ Fusco (2015) places the blame on the flawed and insufficient theoretical work being conducted; other scientific or sociohistorical reasons will not be addressed here.
}

presence of Evo-Devo (with varying degrees) is, probably, the commonest constituent of all (e.g., Pigliucci 2007; Müller 2007b, 2014; Carroll 2008; Weber 2011), with a shared need to explain the nature and origin of organic form (Love 2017). Despite its epistemic uncertainties, Evo-Devo has achieved a great degree of maturity and recently has been portrayed as a 'trading zone' (sensu Peter Galison) due to the complex co-existence of a "variety of disciplines, styles, and paradigms negotiating heavily with one another" (Winther 2015b; p. 459). Given the relentless 'coming of age' of the discipline, the time is right to start posing questions about its formal relationships to the EES: How much of Evo-Devo is actually present (integrated or floating isolated) in the current characterizations (i.e., Laland et al. 2015) of the EES? Is it true that "Evo-Devo shapes the Extended Synthesis"? (as claimed in the title of Müller 2014). How the included key themes and epistemic units of Evo-Devo are contributing to shape and alter the trajectories of that nascent framework? Which key themes and epistemic units are foreshadowed or plainly absent? How international practicing scientists of the burgeoning Evo-Devo community are using (or abstaining to use) the framework of the EES in the design of experiments and/or in the interpretation of empirical data?

Not long ago, Gerd Müller remarked that it is still early to grasp the precise appearance of the EES, but it will surely include "an account of the evolution of novelty and complexity, and the dominance of the variation-in-populations approach will recede. Such change entails significant shifts in theory structure, accounting-among other factors-for the dynamics of development, multiple levels of selection, different forms of inheritance, and reciprocity between environment and organismal activity" (Müller 2014; p. 121). Laland et al. (2015) asserted clearly the importance of developmental constructive processes in evolution, and it has been said before that one of the critical aims of the EES is to identify and explain the causal forces of developmental mechanisms that have an essential role in the evolution of organic form (Pigliucci and Müller 2010b; Martínez and Esposito 2014). Just by looking at the pronouncements in the selected references above, one may argue that Evo-Devo's most simple and fundamental tenet (i.e., knowledge of development is mandatory to fully understand evolutionary processes; stated in Hall 1992; Wagner 2000), is undeniably present in the current state of the EES. But does this mean that the notion of 'constructive development' (CD; sensu Laland et al. 2015) is one of the main contributions of EvoDevo to the EES? We regard that view as inaccurate and partial. Several elements are encapsulated in the notion of $\mathrm{CD}$ : non-programmed ontogenies that co-construct its own developmental trajectories (internal and external states) by means of plastically responding to, integrating and shaping environmental cues with causal parity and reciprocal causation. Furthermore, for Laland et al. (2015; p. 6), "the 
developing organism cannot be reduced to separable components, one of which (e.g., the genome) exerts exclusive control over the other (e.g., the phenotype). Rather, causation also flows back from 'higher' (i.e., more complex) levels of organismal organization to the genes (e.g., tissue-specific regulation of gene expression)." CD does not a assume a bijective function (i.e., a one-to-one correspondence) between genotype and phenotype, nor grants causal privilege and programmatic jurisdiction to genes driving individual development; instead, the developmental system is viewed as responding flexibly and creatively to internal and external inputs, through condition-dependent gene expression, and through physical properties of cells and tissues and 'exploratory behaviors' of several systems. To say it with their adagio: "Organisms are not built from genetic 'instructions' alone, but rather self-assemble using a broad variety of inter-dependent resources" (Laland et al. 2015; p. 6). Taking those views into account, ${ }^{14}$ we argue that the notion of (constructive) development (as used by Laland et al. 2015) cannot be derived entirely from Evo-Devo; it stems from many sources, including developmental systems theory (Oyama 1986), studies of cognition and behavior (see Gottlieb 1992; Oyama et al. 2001), developmental plasticity ${ }^{15}$ (see West-Eberhard 2003) and, of course, evolutionary developmental biology. The preceding statement gains more ground when we recognize that the very notion of 'development' is contentious for developmental biology and EvoDevo (see Minelli and Pradeu 2014). We therefore think that the concept of CD (crucial for Laland et al. 2015) is not the same notion of 'development' most Evo-Devo practitioners and developmental biologists have in mind (they usually harbor a multiplicity of heterogeneous concepts and operational definitions of development, if one at all; see Pradeu et al. 2016). Not many evodevoists conceptualize developing organisms as hierarchical systems (in which different levels of organization interact in complex ways) that result from interactive and co-constructive processes and causes

\footnotetext{
14 We have selected, for the consideration of the reader, three additional fragments of Laland et al. (2015) where the prominence of developmental processes and developmental frameworks is patent: "Parent-offspring similarity occurs not only because of transmission of DNA, but because parents transfer a variety of developmental resources that enable reconstruction of developmental niches"( $p$. 4); "Niche construction also influences ontogeny and constitutes an important way in which environmental factors are incorporated into normal development, sometimes to become as dependable as genomic factors" (p. 4); "Too much causal significance is afforded to genes and selection, and not enough to the developmental processes that create novel variants, contribute to heredity, generate adaptive fit, and thereby direct the course of evolution" (p. 6).

15 Laland and collaborators consider that Evo-Devo is in no position to subsume or engulf the study of developmental plasticity (see Laland et al. 2015).
}

(e.g., evolutionary, ecological, developmental), and not mere products of closed or partially open genetic programs; even fewer evodevoists would go as far as to embrace the principle of causal parity. Likewise, it has been stressed that most of contemporary Evo-Devo research is not 'Devo research' per se, but is focused predominantly on genetics/genomics and new sophisticated molecular methods, concealing development to the background (Diogo 2016). In the words of Armin Moczek (2012), in current Evo-Devo we see "Too many genes, too little development" (p. 116).

We now focus our attention to other presently incorporated and absent epistemic units of Evo-Devo in the EES. A recurring theme in Laland et al. (2015) is the attention given to the fact that phenotypic variation can be biased by the processes and dynamics of development, channeling the evolution (i.e., increasing the probability of occurrence) of certain functional forms and restricting the possible space of realized forms. Developmental bias (e.g., the nonrandom numbers of meristic elements in the body plans of metazoans) is, by far, the most frequently deployed epistemic unit of Evo-Devo in the discussion of the structure and assumptions of the EES in Laland et al. (2015). Another important key theme for Evo-Devo, facilitated variation (see Kirschner and Gerhart 2005), is used as a conceptual scaffold for explaining the existence of phenotypic variation that is channeled and directed toward functional types (developmental bias): the 'core processes' of development concurrently exhibit high robustness and exploratory behaviors that allow them to stabilize and select certain states over others (Laland et al. 2015). Additional key themes of Evo-Devo are marginally mentioned throughout the discussion: for instance, we see the recognition of the existence of modularity in developmental systems and differential coupling and decoupling of phenotypic modules (p. 3); it is mentioned once in the text that phenotypic variation is often the result of alterations in the timing, location, amount or type of gene products brought about by changes in gene regulatory machinery ( $\mathrm{p}$. 3; processes that Wallace Arthur has organized under the label 'developmental repatterning'; see Arthur 2011). The important issue of the evolvability of biological systems, a fundamental topic for Post-Dahlem evolutionary biology (see Wagner 2015), even portrayed by some evodevoists as the proper focus of their discipline (see Hendrikse et al. 2007), appears in the tables and figures of the article, but with only one mention in the corpus of the text (Laland et al. 2015; p. 3). In summary, Evo-Devo ideas discussed in Laland et al. (2015) represent a small fraction of the themes and concepts that, throughout recent history, have been deemed important or fundamental for the discipline. We have prepared a non-exhaustive list of such key themes in Table 1. Of all the terms listed in Table 1, only developmental bias, facilitated variation, and to a considerable lesser extent, modularity and evolvability were used as epistemic 
Table 1 A non-exhaustive list of key themes that have been deemed important or fundamental at some point of the history of the field of EvoDevo

\begin{tabular}{|c|c|c|}
\hline $\begin{array}{l}\text { Developmental bias/developmental con- } \\
\text { straint (Martínez 2009; Caponi 2012; Müller } \\
\text { 2014) }\end{array}$ & $\begin{array}{l}\text { Facilitated variation (Kirschner and Gerhart } \\
\text { 2005; Müller 2014) }\end{array}$ & $\begin{array}{l}\text { Evolvability (Hendrikse et al. 2007; Müller } \\
\text { 2007b; Wagner 2015) }\end{array}$ \\
\hline $\begin{array}{l}\text { Phenotypic plasticity (West-Eberhard 2003; } \\
\text { Sommer 2009) }\end{array}$ & $\begin{array}{l}\text { Modularity (von Dassow and Munro 1999; } \\
\text { Callebaut and Rasskin-Gutman 2005; Müller } \\
\text { 2014) }\end{array}$ & Developmental symbiosis (Gilbert et al. 2015) \\
\hline $\begin{array}{l}\text { Homology (Wagner 2014)/homology thinking } \\
\text { (Wagner 2016) }\end{array}$ & $\begin{array}{l}\text { Deep homology (Shubin et al. 2009; Held } \\
\text { 2017) }\end{array}$ & $\begin{array}{l}\text { Character identity networks (ChINs; Wagner } \\
\text { 2007, 2014) }\end{array}$ \\
\hline Pleiotropy (Pavličev and Wagner 2012) & Robustness (Bateson and Gluckman 2011) & $\begin{array}{l}\text { Genetic tool-kit (Carroll et al. 2001; Wilkins } \\
\text { 2014) }\end{array}$ \\
\hline Developmental repatterning (Arthur 2011) & $\begin{array}{l}\text { Heterochrony (Raff and Wray 1989; McKinney } \\
\text { and McNamara 1991) }\end{array}$ & $\begin{array}{l}\text { Gene regulatory network evolution (Davidson } \\
\text { 2006; Carroll 2008; Rebeiz et al. 2015) }\end{array}$ \\
\hline $\begin{array}{l}\text { Innovation triad (origination, innovation, nov- } \\
\text { elty; Müller and Newman 2005) }\end{array}$ & Epigenetic innovation (Müller 2014) & $\begin{array}{l}\text { Dynamical patterning modules (DPMs; New- } \\
\text { man and Bhat 2009) }\end{array}$ \\
\hline $\begin{array}{l}\text { Generic self-organizing properties of develop- } \\
\text { mental systems (Newman 2003) }\end{array}$ & Body plan (Arthur 1997; Willmore 2012) & $\begin{array}{l}\text { Developmental system drift (True and Haag } \\
\text { 2001; Müller 2014) }\end{array}$ \\
\hline $\begin{array}{l}\text { Phylotypic stage/developmental hourglass (Irie } \\
\text { and Kuratani 2014; Wagner 2015) }\end{array}$ & Gene co-option (Arthur 2002) & Internal selection (Arthur 2002; Caponi 2012) \\
\hline Emergence (Müller 2007b) & Generative entrenchment/burden (Arthur 2002) & Organization (Müller 2007b) \\
\hline
\end{tabular}

According to some authors, each cell in the table is a putative epistemic unit of Evo-Devo (although we recognize some of them overlap). Bold text highlights the epistemic units that were consistently used in Laland et al. (2015)

units by Laland et al. (2015) to outline the structure and assumptions of the EES. ${ }^{16}$

The potential for including more themes of evolutionary developmental biology and developmental evolution to the EES is enormous. Right now, we see the sum of the epistemic units of Evo-Devo incorporated in the EES as an 'early ontogenetic stage' with multiple open developmental trajectories. In a forthcoming, mature EES, for example, epistemic units of Evo-Devo (e.g., evolvability, developmental

\footnotetext{
$\overline{16}$ Eva Jablonka and Marion Lamb (pers. comm, July 2017) raised the concern that, by focusing on "just one paper", we may be acting uncharitable or unfairly to gauge the contributions of Evo-Devo (or of any other research field) to the EES; that to settle the matter of the relative contributions of different fields of research to the structure of the EES, we should wait for a full-length exposition, similar to Huxley's 1942 book, to appear. Although we agree with them (and encourage them to take up to task to write such book) in the sense that our philosophical analysis about the structure of the EES is preliminary and somewhat sketchy, we need to stress that it is just a response to one of the objectives laid out explicitly in Laland et al. (2015: p. 3): "Our objective here is to add substance to these debates by providing a clear statement of the structure, assumptions and predictions of the EES that is useful to both enthusiasts and skeptics, allowing its status as an alternative conceptual framework to be evaluated". We shall add that theory presentations (see Griesemer 1984) are not philosophically innocuous as they reflect how scientists use their frameworks in practice and further demonstrate "how different structures are adopted to achieve specific methodological and epistemological goals in evolutionary theory" (Love 2017; p. 161) by means of idealizing some features while ignoring or concealing to the background other properties or variables of the systems under scrutiny (see also Love 2013).
}

bias, modularity, but also generative entrenchment, genetic tool-kit, GRN evolution, ChINs, DPMs) could be deployed, alongside epistemic units pertaining to niche construction theory and the views of inclusive inheritance and multilevel causation, to generate integrative explanatory frameworks that tackle macroevolutionary problems such as the evolution and diversification of bilaterian body plans in the early Cambrian (i.e., the so-called 'Cambrian Explosion'). A good example of what we think are steps in that direction is the recent framework proposed by Laubichler and Renn (2015) to integrate regulatory networks and niche construction, designed to be equally applicable to cases of biological, social and cultural evolution. The semantic field of the concept of $\mathrm{CD}$, as currently used in the EES (Laland et al. 2015), could also be enriched by augmenting the epistemic units derived from Evo-Devo, also following Laubichler and Renn (2015). Finally, proposals for a 'theory of theory integration' sensu Laubichler et al. (2018) could be contrasted with our philosophical treatment of explanatory and theoretical integration in the EES—based on the works of Brigandt and Love - to foster additional discussions.

\section{Concluding remarks}

We do not interpret the EES as a continuous add-on extension of the SET, where whole new fields, concepts, models and theories are coalescing around a Neo-Darwinian core. Moreover, we do not consider that the EES looks like a bona fide extension at all, as its name implies. It seems that 
only specific epistemic units, derived from Evo-Devo, niche construction theory, the study of developmental plasticity, Jablonka and Lamb's 'evolution in four dimensions' framework and certain elements of the SET, are being deployed by the proponents of the EES to outline its structure (see Laland et al. 2015). In the alternative image we have presented here, the EES could be articulated around a non-static network (or networks, perhaps) of evolutionary models, practices and representation systems, with edges and nodes that change their position and centrality following the developments of evolutionary biology and allied scientific disciplines. We further propose that the cohesive factor that connects these heterogeneous epistemic units is a set of shared epistemic goals-in particular, an understanding and acceptance of the constructive roles organisms play in shaping their own development and in changing their environments in evolutionary meaningful ways. We are aware that a challenge for the future will be to define with precision what constitutes an epistemic unit of the emerging EES (i.e., which criteria should be used to delimit the nodes of the network), if we want to move beyond philosophical abstraction and start engaging with the actual problems addressed by evolutionary biologists. While that philosophical work is underway, we also want to invite (other) philosophers of science and evolutionary biologists (especially Evo-Devo practitioners) to further suggest how Evo-Devo concepts and themes can be used as epistemic units for the consolidation of a pluralistic and integrative EES. Finally, we want to stress that, beyond worn-out Kuhnian or Lakatosian schemes, different philosophical insights are needed to better understand the interdisciplinary reconfiguration of evolutionary theories that are also opening to different fields of inquiry in the social and human sciences (for instance, a potential dialogue with anthropology; see Ingold 2018; pp. 104-105: see also Fuentes 2016). To better understand the emerging structure and the crucially important evolutionary processes emphasized by the Extended Evolutionary Synthesis, let's not settle for ready-made philosophical solutions.

Acknowledgements The authors acknowledge the advice and assistance of Fátima Sofía Ávila-Cascajares during the conception of Fig. 1, and thank Casandra Lizbeth Méndez-Martínez for her aid in the design of Fig. 1. Diana Martínez Almaguer and Julio César Montero Rojas (Graphic Design Unit, Instituto de Biología, UNAM) assisted in the design of all figures of the article. We also thank Mario Casanueva for discussions and his critical remarks about the structure of the EES. The comments and feedback received from Alan Love and Kevin Laland during the presentation of this work at the 2017 Meeting of the International Society for History, Philosophy and Social Studies of Biology (ISHPSSB) in São Paulo, Brazil, were valuable for the preparation of revised versions of this work; at the same meeting, we also benefited from conversations with Eva Jablonka, Marion Lamb and Jan Baedke about the sociological, epistemological and political dimensions involved in the EES debate. AFT is indebted to participants in the poster session of the Sixth Meeting of the European Society for Evolutionary Developmental Biology (Uppsala, July 2016), especially to Mark Jonas. AFT also thanks Francesco Suman for comments on an earlier version of this manuscript and discussions on the structure of the EES and the pluralist landscape of contemporary evolutionism (Washington D.C., September 2016). FVS acknowledges facilities provided by libraries at the Instituto de Biología, UNAM and other academic institutions in Mexico City, Uppsala and London during his long-term research projects on the historiography, epistemology and sociology of biology. Finally, we thank an anonymous reviewer for critical comments which substantially improved the original manuscript. The authors declare that they have no conflict of interest, and that they did not receive any specific funding during the research and writing of this work.

\section{References}

Abouheif E, Sears K (2015) It's time to get together: announcing the new society for evolutionary developmental biology in the Americas. Evol Dev 17:1. https://doi.org/10.1111/ede.12114

Amundson R (2005) The changing role of the embryo in evolutionary thought. Cambridge University Press, Cambridge

Arthur W (1997) The origin of animal body plans. Cambridge University Press, Cambridge

Arthur W (2002) The emerging conceptual framework of evolutionary developmental biology. Nature 415:757-764

Arthur W (2011) Evolution: a developmental approach. Wiley, Hoboken

Bateson P, Gluckman P (2011) Plasticity, robustness, development and evolution. Cambridge University Press, Cambridge

Bonduriansky R (2012) Rethinking heredity, again. Trends Ecol Evol 27:330-336

Bonduriansky R, Day T (2018) Extended Heredity. A New Understanding of Inheritance and Evolution. Princeton University Press, Princeton and Oxford

Bonner JT (ed) (1982) Evolution and development. Springer, Berlin

Brigandt I (2010) Beyond reduction and pluralism: toward an epistemology of explanatory integration in biology. Erkenntnis 73:295-311

Brigandt I, Love AC (2010) Evolutionary novelty and the Evo-Devo synthesis: field notes. Evol Biol 37:93-99

Brigandt I, Love AC (2012) Conceptualizing evolutionary novelty: moving beyond definitional debates. J Exp Zool B Mol Dev Evol 318:417-427

Brooks DR (2011) The extended synthesis: something old, something new. Evol Edu Outreach 4:3-7. https://doi.org/10.1007/s1205 2-010-0304-3

Burian RM (1988) Challenges to the evolutionary synthesis. In: Hecht MK, Wallace B (eds) Evolutionary biology, vol 23. Springer, New York, pp 247-269

Callebaut W (2010) The dialectics of dis/unity in the evolutionary synthesis and its extensions. In: Pigliucci M, Müller GB (eds) Evolution: the extended synthesis. MIT Press, Boston, pp 443-481

Callebaut W, Rasskin-Gutman D (eds) (2005) Modularity: understanding the development and evolution of natural complex systems. MIT Press, Cambridge

Caponi G (2012) Réquiem por el centauro. Aproximación epistemológica a la biología evolucionaria del desarrollo. Centro de Estudios Filosóficos, Políticos y Sociales Vicente Lombardo Toledano, México

Carroll SB (2008) Evo-Devo and an expanding evolutionary synthesis: a genetic theory of morphological evolution. Cell $134: 25-36$ 
Carroll SB, Grenier JK, Weatherbee SD (2001) From DNA to diversity: molecular genetics and the evolution of animal design. Blackwell Science, Malden

Casanueva M (2016) Redes y paisajes conceptuales en la Evo-Devo. Metatheoria 5:83-97

Casanueva M, Martínez M (2014) Marcos causales y síntesis teóricas. Acta Scientiae 16:330-344

Charlesworth D, Barton NH, Charlesworth B (2017) The sources of adaptive variation. Proc Biol Sci 284:20162864. https://doi. org/10.1098/rspb.2016.2864

Craig L (2010) The so-called extended synthesis and population genetics. Biol Theory 5:117-123

Craig LR (2015) Neo-Darwinism and Evo-Devo: an argument for theoretical pluralism in evolutionary biology. Perspect Sci 23:243-279

Danchin E (2013) Avatars of information: towards an inclusive evolutionary synthesis. Trends Ecol Evol 28:351-358

Darden L (1986) Relations among fields in the evolutionary synthesis. In: Bechtel W (ed) Integrating scientific disciplines. Nijhoff Publishers, Dordrecht, pp 113-123

Davidson EH (2006) The regulatory genome: gene regulatory networks in development and evolution. Academic Press, San Diego

Delisle RG (2009) Les philosophies du néodarwinisme: Conceptions divergentes sur l'homme et le sens de l'évolution. Presses Universitaires de France, Paris

Delisle RG (2018) From Charles Darwin to the evolutionary synthesis: weak and diffused connections only. In: Delisle RG (ed) The Darwinian tradition in context. Research programs in evolutionary biology. Springer, Cham, pp 133-167

Depew DJ, Weber BH (2011) The fate of Darwinism: evolution after the modern synthesis. Biol Theory 6:89-102

Depew DJ, Weber BH (2013) Challenging Darwinism: expanding, extending, replacing. In: Ruse M (ed) The Cambridge encyclopedia of Darwin and evolutionary thought. Cambridge University Press, Cambridge, pp 405-411

Dieckmann U, Doebeli M (2005) Pluralism in evolutionary theory. J Evol Biol 18:1209-1213

Diogo R (2016) Where is the Evo in Evo-Devo (evolutionary developmental biology)? J Exp Zool B Mol Dev Evol 326:9-18

Duboule D (2010) The Evo-Devo comet. EMBO Rep 11:489

Eldredge N (1985) Unfinished synthesis: biological hierarchies and modern evolutionary thought. Oxford University Press, Oxford

Eldredge N (2008) Hierarchies and the sloshing bucket: toward the unification of evolutionary biology. Evol Edu Outreach 1:10-15

Eldredge N, Pievani T, Serrelli E, Tëmkin I (eds) (2016) Evolutionary theory: a hierarchical perspective. University of Chicago Press, Chicago

Endler JA, McLellan T (1988) The processes of evolution: toward a newer synthesis. Annu Rev Ecol Evol 19:395-421

Fábregas-Tejeda A, Vergara-Silva F (2018) Hierarchy theory of evolution and the extended evolutionary synthesis: some epistemic bridges, some conceptual rifts. Evol Biol 45:127-139

Feyerabend P (1975) Against method. New Left Books, London

Fuentes A (2016) The extended evolutionary synthesis, ethnography, and the human niche: toward an integrated anthropology. Current Anthropology 57(S13):S13-S26

Fusco G (2015) For a new dialogue between theoretical and empirical studies in evo-devo. Front Ecol Evolut. https://doi.org/10.3389/ fevo.2015.00097

Futuyma DJ (2015) Can modern evolutionary theory explain macroevolution? In: Serrelli E, Gontier N (eds) Macroevolution. Explanation, interpretation and evidence. Springer, Cham, pp 29-85

Futuyma DJ (2017) Evolutionary biology today and the call for an extended synthesis. Interface Focus 7(5):20160145. https://doi. org/10.1098/rsfs.2016.0145
Gaddis JL (2002) The landscape of history. How historians map the past. Oxford University Press, Oxford

Gilbert SF, Bosch TCG, Ledón-Rettig C (2015) Eco-Evo-Devo: developmental symbiosis and developmental plasticity as evolutionary agents. Nat Rev Genet 16:611-622

Gottlieb G (1992) Individual development and evolution. Oxford University Press, Oxford

Gould SJ (1980) Is a new and general theory of evolution emerging? Paleobiology 6:119-130

Gould SJ (2002) The structure of evolutionary theory. Harvard University Press, Cambridge

Grant B (2010) Should evolutionary theory evolve? Sci 24:24-31

Griesemer JR (1984) Presentations and the status of theories. In: Asquit PD, Kitcher P (eds) Proceedings of the 1984 Biennial meeting of the philosophy of science association, vol 1. Philosophy of Science Association, East Lansing, pp 102-114

Hacking I (1979) Imre Lakatos's philosophy of science. Brit J Philos Sci 30:381-402

Hall BK (1992) Evolutionary developmental biology. Chapman \& Hall, London

Handschuh S, Mitteroecker P (2012) Evolution - the extended synthesis. A research proposal persuasive enough for the majority of evolutionary biologists? Hum Ethol Bull 27:18-21

Held LI (2017) Deep homology? Uncanny similarities of humans and flies uncovered by Evo-Devo. Cambridge University Press, Cambridge

Hendrikse JL, Parsons TE, Hallgrímsson B (2007) Evolvability as the proper focus of evolutionary developmental biology. Evol Dev 9:393-401

Hoekstra HE, Coyne JA (2007) The locus of evolution: Evo Devo and the genetics of adaptation. Evolution 61:995-1016

Irie N, Kuratani S (2014) The developmental hourglass model: a predictor of the basic body plan? Development 141:4649-4655

Ingold T (2018) Anthropology: Why It Matters. Polity Press, Cambridge

Jablonka E, Lamb MJ (2007) Précis of evolution in four dimensions. Behav Brain Sci 30:353-389

Jablonka E, Lamb MJ (2014) Evolution in four dimensions. Genetic, epigenetic, behavioral, and symbolic variation in the history of life (revised edition). MIT Press, Cambridge

Jaeger J, Laubichler M, Callebaut W (2015) The comet cometh: evolving developmental systems. Biol Theory 10:36-49

Kellert SH, Longino HE, Waters CK (2006) Introduction: the pluralist stance. In: Kellert SH, Longino HE, Waters CK (eds) Scientific pluralism. University of Minnesota Press, Minneapolis, pp vii-xxviii

Kiger PJ (2016) Is it time for our understating of evolution to evolve? HowStuffWorks website. http://science.howstuffworks.com/life/ evolution/extended-evolutionary-synthesis-theory.htm. Accessed 1 July 2017

Kirschner MW, Gerhart JC (2005) The plausibility of life: resolving Darwin's dilemma. Yale University Press, Yale

Kutschera U, Niklas KJ (2004) The modern theory of biological evolution: an expanded synthesis. Naturwissenschaften 91:255-276

Lakatos I (1978) The methodology of scientific research programmes. Philosophical papers, vol 1. Cambridge University Press, Cambridge

Laland KN, O'Brien M (2012) Cultural niche construction: an introduction. Biol Theory 6:191-202

Laland K, Uller T, Feldman MW, Sterelny K, Müller GB, Moczek A, Jablonka E, Odling-Smee J, Wray GA, Hoekstra HE, Futuyma DJ, Lenski RE, Mackay TF, Schulter D, Strassmann JE (2014) Does evolutionary theory need a rethink? Nature 514:161-164

Laland K, Uller T, Feldman MW, Sterelny K, Müller GB, Moczek A, Jablonka E, Odling-Smee J (2015) The extended evolutionary synthesis: its structure, assumptions and predictions. Proc 
R Soc Lond B Biol Sci 282:20151019. https://doi.org/10.1098/ rspb.2015.1019

Laland K, Matthews B, Feldman MW (2016) An introduction to niche construction theory. Evol Ecol 30:191-202

Laubichler MD (2010) Evolutionary developmental biology offers a significant challenge to the neo-Darwinian paradigm. In: Ayala FJ, Malden RA (eds) Contemporary debates in philosophy of biology. Wiley, Massachusetts, pp 199-212

Laubichler MD, Renn J (2015) Extended evolution: a conceptual framework for integrating regulatory networks and niche construction. J Exp Zool B Mol Dev Evol 324:565-577

Laubichler MD, Prohaska SJ, Stadler PF (2018) Toward a mechanistic explanation of phenotypic evolution: the need for a theory of theory integration. J Exp Zool (Mol Dev Evol) 330:5-14

Lewens T (2016) The meaning of science. An introduction to the philosophy of science. Basic Books, New York

Love AC (2008) Explaining evolutionary innovation and novelty: criteria of adequacy and multidisciplinary prerequisites. Philos Sci 75:874-886

Love AC (2010) Rethinking the structure of evolutionary theory for an extended synthesis. In: Pigliucci M, Müller GB (eds) Evolution: the extended synthesis. MIT Press, Boston, pp 403-441

Love AC (2013) Theory is as theory does: scientific practice and theory structure in biology. Biol Theory 7:325-337

Love AC (2017) Evo-Devo and the structure(s) of evolutionary theory: a different kind of challenge. In: Huneman P, Walsh DM (eds) Challenging the modern synthesis. Adaptation, development, and inheritance. Oxford University Press, New York, pp 159-187

Lynch M (2007) The origins of genome architecture. Sinauer Associates, Sunderland

Martínez M (2009) Los constreñimientos del desarrollo y la integración EvoDevo: precisiones y distinciones en torno al tema. Acta Biol Colomb 14S:151-168

Martínez M, Esposito M (2014) Multilevel causation and the extended synthesis. Biol Theory 9:209-222

Mayr E (1963) Animal species and evolution. Harvard University Press, Cambridge

Mayr E (2004) What makes biology unique? Considerations on the autonomy of a scientific discipline. Cambridge University Press, Cambridge

McKinney ML, McNamara KJ (eds) (1991) Heterochrony: the evolution of ontogeny. Plenum Press, New York

Minelli A (2010) Evolutionary developmental biology does not offer a significant challenge to the neo-Darwinian paradigm. In: Ayala FJ, Malden RA (eds) Contemporary debates in philosophy of biology. Wiley, Massachusetts, pp 213-226

Minelli A, Pradeu T (eds) (2014) Towards a theory of development. Oxford University Press, Oxford

Moczek AP (2012) The nature of nurture and the future of evodevo: toward a theory of developmental evolution. Integr Comp Biol $52: 108-119$

Müller GB (2007a) Six memos for Evo-Devo. In: Laubichler MD, Maienschein J (eds) From embryology to Evo-Devo: a history of developmental evolution. MIT Press, Cambridge, pp 499-524

Müller GB (2007b) Evo-devo: extending the evolutionary synthesis. Nat Rev Genet 8:943-949

Müller GB (2014) EvoDevo shapes the extended synthesis. Biol Theory 9:119-121

Müller GB (2017) Why an extended evolutionary synthesis is necessary. Interface Focus 7(5):20170015. https://doi.org/10.1098/ rsfs.2017.0015

Müller GB, Newman SA (2005) The innovation triad: an EvoDevo agenda. J Exp Zool Mol Dev Evol 304:487-503

Nei M (2013) Mutation-driven evolution. Oxford University Press, Oxford
Newman SA (2003) From physics to development: the evolution of morphogenetic mechanisms. In: Müller GB, Newman SA (eds) Origination of organismal form. MIT Press, Cambridge, pp 221-239

Newman SA, Bhat R (2009) Dynamical patterning modules: a "pattern language" for development and evolution of multicellular form. Int J Dev Biol 53:693-705

Nicholson DJ, Gawne R (2015) Neither logical empiricism nor vitalism, but organicism: what the philosophy of biology was. Hist Philos Life Sci 37:281-345

Noble D (2015) Evolution beyond neo-Darwinism: a new conceptual framework. J Exp Biol 218:7-13

Noble D, Jablonka E, Joyners MJ, Müller GB, Omholt SW (2014) Evolution evolves: physiology returns to centre stage. J Physiol 592:2237-2244

Nuño de la Rosa L (2014) On the possible, the conceivable, and the actual in evolutionary theory. Biol Theory 9:221-228

Nuño de la Rosa L (2017) Computing the extended synthesis: mapping the dynamics and conceptual structure of evolvability research front. J Exp Zool B Mol Dev Evol 328:395-411

Odling-Smee FJ, Laland KN, Feldman MW (2003) Niche construction: the neglected process in evolution. Princeton University Press, Princeton

Oyama S (1986) The ontogeny of information. Cambridge University Press, Cambridge

Oyama S, Griffiths PE, Gray RD (eds) (2001) Cycles of contingency: developmental systems and evolution. MIT Press, Massachusetts

Palma H (2015) Origen, actualidad y prospectiva de la filosofía de la biología. CTS 28:123-140

Pavličev M, Wagner GP (2012) A model of developmental evolution: selection, pleiotropy and compensation. Trends Ecol Evol 27:316-322

Pavličev M, Wagner GP (2015) Evolutionary systems biology: shifting focus to the context-dependency of genetic effects. In: Martin LB, Ghalambor GK, Woods HA (eds) Integrative organismal biology. Wiley, Hoboken, pp 91-108

Pennisi E (2008) Modernizing the modern synthesis. Science 321:196-197

Pennisi E (2016) Templeton grant funds evolution rethink. Science 352:394-395

Peterson EL (2016) The life organic: the theoretical biology club and the roots of epigenetics. University of Pittsburgh Press, Pittsburgh

Pievani T (2012) An evolving research programme: the structure of evolutionary theory from a lakatosian perspective. In: Fasolo A (ed) The theory of evolution and its impact. Springer, Italia, pp 211-228

Pievani T (2016a) How to rethink evolutionary theory: a plurality of evolutionary patterns. Evol Biol 43:446-455. https://doi. org/10.1007/s11692-015-9338-3

Pievani T (2016b) Hierarchy theory and the extended synthesis debate. In: Eldredge N, Pievani T, Serrelli EM, Tëmkin I (eds) Evolutionary theory: a hierarchical perspective. University of Chicago Press, Chicago, pp 351-364

Pigliucci M (2007) Do we need an extended evolutionary synthesis? Evolution 61:2743-2749

Pigliucci M (2009) An extended synthesis for evolutionary biology. Ann N Y Acad Sci 1168:218-228

Pigliucci M (2018) Darwinism after the modern synthesis. In: Delisle RG (ed) The Darwinian tradition in context. Research programs in evolutionary biology. Springer, Cham, pp 98-103

Pigliucci M, Finkelman L (2014) The extended (evolutionary) synthesis debate: where science meets philosophy. Bioscience 64:511-516

Pigliucci M, Müller GB (eds) (2010a) Evolution: the extended synthesis. MIT Press, Boston 
Pigliucci M, Müller GB (2010b) Elements of an extended evolutionary synthesis. In: Pigliucci M, Müller GB (eds) Evolution: the extended synthesis. MIT Press, Boston, pp 3-17

Pradeu T, Laplane L, Prévot K, Hoguet T, Reynaud V, Fusco G, Minelli A, Orgogozo V, Vervoort M (2016) Defining "development". Curr Top Dev Biol 117:171-183

Raff RA, Wray GA (1989) Heterochrony: developmental mechanisms and evolutionary results. J Evol Biol 2:409-434

Raj K (2013) Beyond postcolonialism... and postpositivism: circulation and the global history of science. Isis 104:337-347

Rebeiz M, Patel NH, Hinman VF (2015) Unraveling the tangled skein: the evolution of transcriptional regulatory networks in development. Annu Rev Genomics Hum Genet 16:103-131. https://doi. org/10.1146/annurev-genom-091212-153423

Reiss JO (2012) Footnotes to the synthesis? Metascience 21:163-166

Shubin N, Tabin C, Carroll S (2009) Deep homology and the origins of evolutionary novelty. Nature 457:818-823

Sidlauskas B, Ganapathy G, Hazkani-Covo E, Jenkins KP, Lapp H, McCall LW, Price S, Scherle R, Spaeth PA, Kidd DM (2010) Linking big: the continuing promise of evolutionary synthesis. Evolution 64:871-880

Smocovitis VB (1996) Unifying biology: the evolutionary synthesis and evolutionary biology. Princeton University Press, Princeton

Sommer RJ (2009) The future of Evo-Devo: model systems and evolutionary theory. Nat Rev Genet 10:416-422. https://doi. org/10.1038/nrg2567

Stanley SM (1981) The new evolutionary timetable. Fossils, genes, and the origin of species. Basic Books, New York

Stoltzfus A (2017) Why we don't want another "synthesis". Biol Direct 12:23. https://doi.org/10.1186/s13062-017-0194-1

Suman F (2016) An updated evolutionary research programme for the evolution of language. Topoi. https://doi.org/10.1007/s1124 5-016-9419-7

Svensson EI (2018) On reciprocal causation in the evolutionary process. Evol Biol 45(1):1-14

Tëmkin I, Eldredge N (2015) Networks and hierarchies: approaching complexity in evolutionary theory. In: Serrelli E, Gontier N (eds) Macroevolution: explanation, interpretation, evidence. Springer, Cham, pp 183-226

True JR, Haag ES (2001) Developmental system drift and flexibility in evolutionary trajectories. Evol Dev 3:109-119

von Dassow G, Munro E (1999) Modularity in animal development and evolution: elements of a conceptual framework for EvoDevo. J Exp Zool 285:307-325

Waddington CH (1969) Paradigm for an evolutionary process. In: Waddington $\mathrm{CH}$ (ed) Towards a theoretical biology, vol 2. International Union of Biological Sciences \& Edinburgh University Press, Paris, pp 106-123
Wagner GP (2000) What is the promise of developmental evolution? Part I: Why is developmental biology necessary to explain evolutionary innovations? J Exp Zool B Mol Dev Evol 288:95-98

Wagner GP (2007) The developmental genetics of homology. Nat Rev Genet 8:473-479

Wagner A (2011) The origins of evolutionary innovations. Oxford University Press, Oxford

Wagner GP (2014) Homology, genes and evolutionary innovation. Princeton University Press, Princeton

Wagner GP (2015) Reinventing the organism: evolvability and homology in post-Dahlem evolutionary biology. In: Love AC (ed) Conceptual change in biology. Scientific and philosophical perspectives on evolution and development. Springer, Dordrecht, pp 327-342

Wagner GP (2016) What is "homology thinking" and what is it for? J Exp Zool B Mol Dev Evol 326:3-8

Wassermann GD (1981) On the nature of the theory of evolution. Philos Sci 48:416-437

Weber BH (2011) Extending and expanding the Darwinian synthesis: the role of complex systems dynamics. Stud Hist Philos Biol Biomed Sci 42:75-81

Welch JJ (2017) What's wrong with evolutionary biology? Biol Philos 32:263-279

West-Eberhard MJ (2003) Developmental plasticity and evolution. Oxford University Press, Oxford

Whitfield J (2008) Biological theory: postmodern evolution? Nature 455:281-284

Wicken JS (1987) Evolution, thermodynamics and information: extending the Darwinian program. Oxford University Press, New York

Wilkins A (2014) "The genetic tool-kit": the life-history of an important metaphor. In: Steelman JT (ed) Advances in evolutionary developmental biology. Wiley, Singapore, pp 1-14

Willmore KE (2012) The body plan concept and its centrality in EvoDevo. Evol Edu Outreach 5:219-230

Winther RG (2015a) The structure of scientific theories. In: Zalta EN (ed) The stanford encyclopedia of philosophy (Spring 2016 Edition). http://plato.stanford.edu/archives/spr2016/entries/struc ture-scientific-theories/. Accessed 12 July 2016

Winther RG (2015b) Evo-Devo as a trading zone. In: Love AC (ed) Conceptual change in biology: scientific and philosophical perspectives on evolution and development, boston studies in the philosophy of science, vol 307. Springer, Dordrecht, pp 459-482

Zimmer C (2016) Scientists seek to update evolution. Quanta magazine. https://www.quantamagazine.org/scientists-seek-to-updat e-evolution-20161122. Accessed 1 July 2017 